\title{
Examining for Leisure Barriers for Female Students Studying in the Faculty of Sports Science
}

\section{Mustafa KIZILKOCA ${ }^{1}$ Akif BOZKIR}

${ }_{1,2}$ Faculty of Physical Education and Sport Sciences, Munzur University, Turkey.

'Email:mkizilkoca@munzur.edu.tr

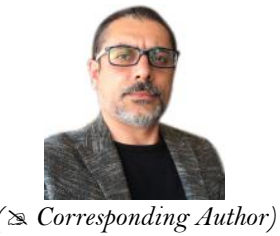

\section{Abstract}

The aim of our study was to examine the levels of leisure barriers of female undergraduate students in the Faculty of Sports Sciences in terms of some demographic characteristics. The participants of our study are 120 randomly selected female undergraduate students who studied at Firat University Faculty of Sports Sciences in 2020. In order to determine the personal characteristics of the participants in the study, a personal information form (Age, Class, Department and Branch) and a scale of leisure barriers developed by Alexandris and Carroll (1997a) and adapted to Turkish by Gürbüz, Öncü, and Emir (2012) were applied. It is seen that the leisure barriers scale scores of female undergraduate students studying in the departments of the Faculty of Sport Sciences of Firat University are above average with an average of 2.79 in the individual psychology sub-dimension and, 2.77 in the lack of knowledge sub-dimension, 3.17 in the facility sub-dimension, 2.58 in the lack of friends sub-dimension, 3.09 in the time subdimension, and 2.85 in the lack of interest sub-dimension according to the findings of the study. It was observed that it was higher than the average with an average of 2.88 , considering the general mean score of the leisure barriers scale.

Keywords: Female, Leisure, Barriers, Student.

Citation | Mustafa KIZILKOCA; Akif BOZKIR (2020). Examining for Leisure Barriers for Female Students Studying in the Faculty of Sports Science. Asian Journal of Education and Training, 6(4): 636641 .

History:

Received: 22 September 2020

Revised: 12 October 2020

Accepted: 29 October 2020

Published: 18 November 2020

Licensed: This work is licensed under a Creative Commons Attribution 3.0 License (c)

Publisher: Asian Online Journal Publishing Group
Acknowledgement: Both authors contributed to the conception and design of the study.

Funding: This study received no specific financial support

Competing Interests: The authors declare that they have no conflict of interests.

Transparency: The authors confirm that the manuscript is an honest, accurate, and transparent account of the study was reported; that no vital features of the study have been omitted; and that any discrepancies from the study as planned have been explained.

study as planned have been explained.
Ethical: This study follows all ethical practices during writing.

\section{Contents}

1. Introduction

3. Findings

637

4. Discussion and Conclusion.

References 


\section{Contribution of this paper to the literature}

The aim of this study is to contribute literature by examining the levels of leisure barriers of female students studying in the faculty of sports sciences.

\section{Introduction}

Humankind has always been in the struggle for survival since the existence of the universe. The humankind has to work constantly for the survival effort to fulfill its vitality and cope with difficulties. People have called the time left over from these harsh conditions of life as leisure. When the society became aware of their leisure, the main purpose was to use this time out of work with activities and at the same time to get rid of the fatigue of daily life mentally and physically. Leisure is defined as the periods when people have weekends and annual holidays other than working days (Turkmen, Kul, Genç, \& Sarıkabak, 2013).

Leisure activities are called leisure activities or recreational activities. These activities are divided into social, intellectual, artistic activities, practical and physical activities by the scientists working in this field (Büküşoğlu \& Bayturan, 2005). It can be said that the activities that society has the most in this period and prefer in terms of health are physical activities. Individuals want to prepare themselves more vigorously and mentally for their new work life by sporting the challenges of life struggle. Physical activities can sometimes be a trekking and sometimes a sporting challenge (Karahuseyinoglu, Altungul, Nacar, \& Tutar, 2020). Recreative activities are sometimes not fulfilled when society needs them. Some factors can prevent this situation by not always being able to meet the wishes of individuals at any time. In this case, we come across the concept of leisure barriers. All of the factors that prevent people from doing activities during leisure periods can be defined as leisure barriers. Researchers define barriers as all factors that reduce participation in leisure and the pleasure of the individual during this activity (Alexandris \& Carroll, 1997a). People are trying to struggle with these barriers. Since this time outside of business life is the period when people feel the best from their mental and physical conditions, it can be a great disappointment to spend this time free.

Leisure barriers will affect people's social and cultural interactions as well as their preparation for the work and education period and their effectiveness in these periods. Since it is thought that students encountering leisure barriers will cause adaptation problems in educational processes, our study is intended to examine the levels of leisure barriers of female undergraduate students in the faculty of sports sciences in terms of some demographic characteristics.

\section{Material and Method}

The universe of research is made up of female undergraduate students studying at Firat University Faculty of Sports Sciences in 2020. Its sample consists of 120 female university students randomly selected from Firat University Sports Sciences Faculty Physical Education, Sports Management, Coaching Education and Recreation Departments.

In order to determine the personal characteristics of the participants in the study, a personal information form (Age, Class, Department and Branch) and a scale of leisure barriers developed by Alexandris and Carroll (1997a) and adapted to Turkish by Gürbüz et al. (2012) were applied. Leisure Barriers Scale is a 4-point Likert type with 18 questions. For each question, 1: "Absolutely Unimportant", 2: "Unimportant", 3: "Important", 4: "Very Important", Various options were suggested and the research team was asked to mark the option that best suits their opinion. The scale consists of 6 sub-dimensions.Sub-dimensions have consisted of mentioned items; Individual psychology sub-dimension from items 1st, 2nd and, 3rd, lack of knowledge sub-dimension from items 4th, 5 th, and 6 th, facility sub-dimension from items 7 th, 8 th, and 9 th, lack of friends sub-dimension 10th, 11 th and 12 th items, time subdimension from items 13th, 14th and 15th, and lack of interest sub-dimension from items 16th, 17 th and, 18th. It was found that the individual psychology sub-dimension was 0.75 , the lack of knowledge was 0.74 , the facility was 0.72 , the lack of friends was 0.65 , and the time sub-dimension was 0.61 and 0.63 in the lack of interest subdimension when the Cronbach's Alpha $(\alpha)$ reliability coefficient values of the sub-dimensions of the Leisure Barriers scale were examined. These values indicate that scores from the scale are highly reliable. The scoring values of the scale are based on the scale ruler of 5 .

\subsection{Analysis of Data}

SPSS 22.0 statistics program was used to analyze the data in the study and calculate the results. Skewness and kurtosis tests were used to determine whether the data provided normal distribution. As a result of these tests and controls, it was determined that the research data were parametric. In this case, a two-way analysis of variance (ANOVA) in multiple group variables and a t test to determine the significance of the difference between two independent groups were used. The Tukey test was used to determine which groups in the analysis detected significant differences. Error level in the study was accepted as $\mathrm{p}<0.05$.

\section{Findings}

This section presents the findings of the study variables. The results showing the distribution of female undergraduate students according to the personal characteristics of Firat University Faculty of Sports Sciences who participated in our research were examined and interpreted.

\subsection{Percentage Distribution of the Subjects}

It is observed that the highest participation is $26.7 \%(\mathrm{n}=32)$ and recreation department students, while the lowest attendance is $23.3 \%(\mathrm{n}=28)$ and the management department is female students when the demographic distribution table of female students is examined in Table 1. The highest participation was female students between the ages of $22-24$ with $46.7 \%$ and, followed by female students between the ages of $19-21$ with 34.2 and finally, female students aged 25 years and older with 19.2 to when looking at the age groups of the participants. When the class distributions in which the participants studied were examined, 4th-grade female students were highly attended with $45.8 \%$, while the lowest participation was $15.0 \%$ for 3 rd-grade students. It was determined that 
42.5\% were engaged in team sports, $41.7 \%$ were interested in individual sports and $15.8 \%$ did not have any branches when the group distribution of the participants was examined in terms of branch variable.

\begin{tabular}{l|l|c|c}
\multicolumn{4}{c}{ Table-1. Demographics related to athletes. } \\
\hline Variable & Group & $\mathbf{N}$ & $\%$ \\
\hline & Teaching & 31 & 25,8 \\
\hline Department & Management & 28 & 23,3 \\
\hline & Coaching & 29 & 24,2 \\
\hline & Recreation & 32 & 26,7 \\
\hline & Total & 120 & 100,0 \\
\hline & $19-21$ Years & 41 & 34,2 \\
\hline & 22-24 Years & 56 & 46,7 \\
\hline Age & 25 years and older & 23 & 19,2 \\
\hline & Total & 120 & 100,0 \\
\hline & 1 st Class & 22 & 18,3 \\
\hline Class & 2nd Class & 25 & 20,8 \\
\hline & 3rd Class & 18 & 15,0 \\
\hline & 4th Class & 55 & 45,8 \\
\hline & Total & 120 & 100,0 \\
\hline Branch & Team Sports & 51 & 42,5 \\
\hline & Individual Sports & 50 & 41,7 \\
\hline & Branchless & 19 & 15,8 \\
\hline Note: N:120. & Total & 120 & 100,0 \\
\hline & & &
\end{tabular}

Table-2. Anova test results based on the variable of the departments in which the participants in the study studied.

\begin{tabular}{|c|c|c|c|c|c|c|}
\hline Sub-Dimensions & Department & $\mathbf{N}$ & $\mathbf{X}$ & Ss & $\mathbf{F}$ & p \\
\hline \multirow{5}{*}{ Individual Psychology } & Teaching & 31 & 2,80 & 1,02839 &, 077 &, 972 \\
\hline & Coaching & 29 & 2,86 &, 94917 & & \\
\hline & Management & 28 & 2,75 &, 94988 & & \\
\hline & Recreation & 32 & 2,77 & ,87349 & & \\
\hline & Total & 120 & 2,79 &, 94013 & & \\
\hline \multirow{5}{*}{ Lack of Knowledge } & Teaching & 31 & 2,88 & 1,01306 & ,356 &, 785 \\
\hline & Coaching & 29 & 2,81 &, 85257 & & \\
\hline & Management & 28 & 2,64 & 1,01806 & & \\
\hline & Recreation & 32 & 2,76 &, 76778 & & \\
\hline & Total & 120 & 2,77 & ,90886 & & \\
\hline \multirow{5}{*}{ Facility } & Teaching & 31 & 3,32 &, 75269 & 1,894 &, 135 \\
\hline & Coaching & 29 & 3,34 & ,66953 & & \\
\hline & Management & 28 & 2,97 & ,89318 & & \\
\hline & Recreation & 32 & 3,05 &, 62853 & & \\
\hline & Total & 120 & 3,17 &, 74719 & & \\
\hline \multirow{5}{*}{ Lack of Friends } & Teaching & 31 & 2,38 & 1,08217 &, 547 & ,651 \\
\hline & Coaching & 29 & 2,68 &, 92980 & & \\
\hline & Management & 28 & 2,64 & 1,04990 & & \\
\hline & Recreation & 32 & 2,62 &, 97551 & & \\
\hline & Total & 120 & 2,58 & 1,00535 & & \\
\hline \multirow{5}{*}{ Time } & Teaching & 31 & 2,94 &, 91123 &, 610 &, 610 \\
\hline & Coaching & 29 & 3,22 &, 71881 & & \\
\hline & Management & 28 & 3,08 &, 89638 & & \\
\hline & Recreation & 32 & 3,11 &, 73621 & & \\
\hline & Total & 120 & 3,09 & ,81531 & & \\
\hline \multirow{5}{*}{ Lack of interest } & Teaching & 31 & 2,67 & ,99064 &, 761 &, 518 \\
\hline & Coaching & 29 & 2,93 & ,84693 & & \\
\hline & Management & 28 & 2,83 & ,90948 & & \\
\hline & Recreation & 32 & 2,98 &, 72579 & & \\
\hline & Total & 120 & 2,85 & ,86929 & & \\
\hline
\end{tabular}

Note: Anova test, $\mathrm{p}<0.05$

It was found that there was no statistically significant difference between the leisure barriers sub-dimensions of the participants and the variable of the department they studied ( $p>0.05)$ when Table 2 was examined.

It was observed that there was no statistically significant difference between the sub-dimensions of the Leisure Disorder Scale and the facility sub-dimension, lack of friends and lack of interest, and age variables ( $>>0.05)$ when Table 3 was examined. It was determined that the difference between the sub-dimensions of the leisure barrier, individual psychology, lack of information and time, and the age variable was statistically significant $(p<0.05)$.

It was found that there was no statistically significant difference between the individual psychology, lack of information, facility, lack of time and interest sub-dimensions of the leisure barriers scale and the class variable ( $p>$ $0.05)$ when Table 4 was examined. The difference between the lack of friends sub-dimension of the leisure barriers scale and the classroom variable was found to be statistically significant $(\mathrm{p}<0.05)$. 


\begin{tabular}{|c|c|c|c|c|c|c|c|}
\hline Sub-dimensions & Age & $\mathbf{N}$ & $\mathbf{X}$ & Ss & $\mathbf{F}$ & p & Tukey \\
\hline \multirow{4}{*}{ Individual Psychology } & $19-21$ Years $^{A}$ & 41 & 2,53 & 1,06426 & 4,031 &, 020 & \\
\hline & 22-24 Years ${ }^{\mathrm{B}}$ & 56 & 3,04 &, 80511 & & & A-B \\
\hline & 25 Years and older $\mathrm{C}$ & 23 & 2,65 &, 89034 & & & \\
\hline & Total & 120 & 2,79 &, 94013 & & & \\
\hline \multirow{4}{*}{ Lack of Knowledge } & 19-21 Years ${ }^{\mathrm{A}}$ & 41 & 2,54 & 1,06394 & 3,082 & ,050 & \\
\hline & 22-24 Years ${ }^{\mathrm{B}}$ & 56 & 2,98 &, 79128 & & & A-B \\
\hline & 25 Years and older ${ }^{\mathrm{C}}$ & 23 & 2,68 &, 78803 & & & \\
\hline & Total & 120 & 2,77 & ,90886 & & & \\
\hline \multirow{4}{*}{ Facility } & 19-21 Years & 41 & 3,00 & ,99443 & 1,849 &, 162 & \\
\hline & 22-24 Years & 56 & 3,29 &, 53959 & & & \\
\hline & 25 Years and older & 23 & 3,20 &, 63357 & & & \\
\hline & Total & 120 & 3,17 &, 74719 & & & \\
\hline \multirow{4}{*}{ Lack of Friends } & 19-21 Years & 41 & 2,43 & 1,03666 & ,833 & 437 & \\
\hline & 22-24 Years & 56 & 2,61 & 1,02253 & & & \\
\hline & 25 Years and older & 23 & 2,76 & ,90696 & & & \\
\hline & Total & 120 & 2,58 & 1,00535 & & & \\
\hline \multirow{4}{*}{ Time } & 19-21 Years ${ }^{\mathrm{A}}$ & 41 & 2,83 & ,99197 & 3,752 & ,026 & \\
\hline & 22-24 Years ${ }^{\mathrm{B}}$ & 56 & 3,28 & ,67098 & & & A-B \\
\hline & 25 Years and older ${ }^{\mathrm{C}}$ & 23 & 3,07 & ,68133 & & & \\
\hline & Total & 120 & 3,09 & ,81531 & & & \\
\hline \multirow{4}{*}{ Lack of interest } & 19-21 Years & 41 & 2,61 & ,93856 & 2,941 & ,057 & \\
\hline & 22-24 Years & 56 & 2,92 &, 80401 & & & \\
\hline & 25 Years and older & 23 & 3,13 &, 82106 & & & \\
\hline & Total & 120 & 2,85 & ,86929 & & & \\
\hline
\end{tabular}

Note: Anova test, $\mathrm{p}<0.05$

Table-4. Anova test results based on class groups variable of participants in the study.

\begin{tabular}{|c|c|c|c|c|c|c|c|}
\hline Sub-dimensions & Class & $\mathbf{N}$ & $\mathbf{X}$ & Ss & $\mathbf{F}$ & p & Turkey \\
\hline \multirow{5}{*}{ Individual Psychology } & 1st class & 22 & 2,53 & 1,13929 & ,791 &, 501 & \\
\hline & 2nd class & 25 & 2,81 & 1,12250 & & & \\
\hline & 3rd class & 18 & 2,94 &, 95144 & & & \\
\hline & 4th class & 55 & 2,84 &, 74761 & & & \\
\hline & Total & 120 & 2,79 &, 94013 & & & \\
\hline \multirow{5}{*}{ Lack of Knowledge } & 1st class & 22 & 2,51 & 1,16713 &, 942 & ,423 & \\
\hline & 2nd class & 25 & 2,82 & 1,10604 & & & \\
\hline & 3rd class & 18 & 2,98 &, 93216 & & & \\
\hline & 4th class & 55 & 2,79 &, 65575 & & & \\
\hline & Total & 120 & 2,77 & ,90886 & & & \\
\hline \multirow{5}{*}{ Facility } & 1st class & 22 & 3,18 &, 90107 &, 241 & ,868 & \\
\hline & 2nd class & 25 & 3,25 &, 87813 & & & \\
\hline & 3rd class & 18 & 3,05 &, 84211 & & & \\
\hline & 4th class & 55 & 3,17 &, 58392 & & & \\
\hline & Total & 120 & 3,17 &, 74719 & & & \\
\hline \multirow{5}{*}{ Lack of Friends } & 1 st class $^{\mathrm{A}}$ & 22 & 2,33 & 1,09834 & 4,921 & ,003 & \\
\hline & 2nd class $^{\mathrm{B}}$ & 25 & 2,53 & 1,16269 & & & \\
\hline & 3rd class ${ }^{\mathrm{C}}$ & 18 & 1,98 & 1,05702 & & & C-D \\
\hline & 4th class $^{\mathrm{D}}$ & 55 & 2,90 &, 74445 & & & \\
\hline & Total & 120 & 2,58 & 1,00535 & & & \\
\hline \multirow{5}{*}{ Time } & 1st class & 22 & 3,04 &, 95560 & ,459 & ,711 & \\
\hline & 2nd class & 25 & 3,21 &, 87072 & & & \\
\hline & 3rd class & 18 & 2,92 & 1,00036 & & & \\
\hline & 4th class & 55 & 3,10 &, 66374 & & & \\
\hline & Total & 120 & 3,09 &, 81531 & & & \\
\hline \multirow{5}{*}{ Lack of interest } & 1st class & 22 & 2,81 & ,92997 & 2,643 & ,053 & \\
\hline & 2nd class & 25 & 2,84 & 1,05022 & & & \\
\hline & 3rd class & 18 & 2,38 & ,93060 & & & \\
\hline & 4th class & 55 & 3,03 &, 67791 & & & \\
\hline & Total & 120 & 2,85 & ,86929 & & & \\
\hline
\end{tabular}

Note: Anova test, $\mathrm{p}<0.05$.

It was determined that there was no statistically significant difference between the sub-dimensions of individual psychology, lack of knowledge, facility, lack of time and friends, and branch variable from the subdimensions of the participants' leisure barriers scale $(\mathrm{p}>0.05)$ when Table 5 was examined. The difference between the lack of interest sub-dimension, which is one of the sub-dimensions of the leisure time barriers, and the branch variable was found to be statistically significant $(\mathrm{p}<0.05)$.

\section{Discussion and Conclusion}

The results regarding whether the leisure time barrier levels of female undergraduate students studying at Firat University Faculty of Sport Sciences differ according to some variables are discussed and interpreted in this part of our study.

The highest participation was $26.7 \%(\mathrm{n}=32)$ with recreation department students, while the lowest attendance was $23.3 \%(\mathrm{n}=28)$ with female students in the management department when the participants were examined in Table 1. When looking at the age groups of the participants, the highest participation was female students 
between the ages of $22-24$ with $46.6 \%$, followed by female students between the ages of 19-21 with 34.2 and finally female students aged 25 years and older with $19.2 \%$. When the class distributions in which the participants studied were examined, 4th-grade female students were highly attended with $45.8 \%$, while the lowest participation was $15.0 \%$ for $3 \mathrm{rd}$-grade students. It was determined that $42.5 \%$ were engaged in team sports, $41.7 \%$ were interested in individual sports and $15.8 \%$ did not have any branches when the group distribution of the participants was examined in terms of branch variable.

Table-5. Anova test results according to the branch groups variable of the participants in the study.

\begin{tabular}{|c|c|c|c|c|c|c|c|}
\hline Sub-dimensions & Branch & $\mathbf{N}$ & $\mathbf{X}$ & Ss & $\mathbf{F}$ & $\mathrm{p}$ & Turkey \\
\hline \multirow{4}{*}{ Individual Psychology } & Team Sports & 51 & 2,75 &, 97489 &, 500 & 608 & \\
\hline & \begin{tabular}{|l} 
Individual Sports \\
\end{tabular} & 50 & 2,89 &, 86620 & & & \\
\hline & None & 19 & 2,66 & 1,05409 & & & \\
\hline & Total & 120 & 2,79 &, 94013 & & & \\
\hline \multirow{4}{*}{ Lack of Knowledge } & Team Sports & 51 & 2,76 &, 89018 & 1,587 & ,209 & \\
\hline & Individual Sports & 50 & 2,90 &, 83310 & & & \\
\hline & None & 19 & 2,47 & 1,10730 & & & \\
\hline & Total & 120 & 2,77 & ,90886 & & & \\
\hline \multirow{4}{*}{ Facility } & Team Sports & 51 & 3,22 & ,69175 & 1,405 & ,249 & \\
\hline & Individual Sports & 50 & 3,22 &, 66816 & & & \\
\hline & None & 19 & 2,91 & 1,02946 & & & \\
\hline & Total & 120 & 3,17 &, 74719 & & & \\
\hline \multirow{4}{*}{ Lack of Friends } & Team Sports & 51 & 2,70 &, 98126 & 1,998 &, 140 & \\
\hline & Individual Sports & 50 & 2,61 &, 92179 & & & \\
\hline & None & 19 & 2,17 & 1,21395 & & & \\
\hline & Total & 120 & 2,58 & 1,00535 & & & \\
\hline \multirow{4}{*}{ Time } & Team Sports & 51 & 2,99 &, 80413 &, 972 & ,381 & \\
\hline & Individual Sports & 50 & 3,21 & ,69582 & & & \\
\hline & None & 19 & 3,03 & 1,09935 & & & \\
\hline & Total & 120 & 3,09 &, 81531 & & & \\
\hline \multirow{4}{*}{ Lack of interest } & Team Sports ${ }^{A}$ & 51 & 2,76 &, 87507 & 3,181 & 045 & \\
\hline & \begin{tabular}{|l} 
Individual Sports \\
\end{tabular} & 50 & 3,07 &, 74776 & & & $\mathrm{~B}-\mathrm{C}$ \\
\hline & None ${ }^{\mathrm{C}}$ & 19 & 2,54 & 1,04356 & & & \\
\hline & Total & 120 & 2,85 & ,86929 & & & \\
\hline
\end{tabular}

Note: Anova test, $\mathrm{p}<0.05$.

When the sub-dimensions of the leisure time barriers scale and the department variable in which the participants study were examined, it was found that there was no statistically significant difference between the leisure time barriers sub-dimensions and the department they studied ( $p>0.05)$. It is seen that the sub-dimension with the highest average is the sub-dimension of the facility when the sub-dimensions of leisure barriers are examined. Terzioğlu and Yazıcı stated that students had too much free time in a study they conducted in 2003, but they could not use this free time effectively on the understanding and habits of university students in evaluating leisure time; They also stated that students perceive leisure and sports as a means of physical and mental development. In a study that was not parallel to our research conducted by Güler (2017) a significant difference was found in favor of other students in the relationship between physical education students and other students in the level of leisure evaluation and social cohesion. Similar results were obtained in the study conducted by Turkoglu (2009). It has been revealed that physical education teachers and high school students who attend physical education classes have a positive attitude towards the environment. While both physical education teachers and students realized they did not have much time to participate in environmental recreation activities, they concluded that they could keep up with the developments in the media and tried to share the information with their friends.

It was determined that there was no statistically significant difference between the sub-dimensions of the leisure time barriers scale of the participants in the study, and the sub-dimensions of facility, lack of friends and interest, and the age variable ( $p>0.05)$. It was determined that the difference between the sub-dimensions of the leisure time barrier, individual psychology, lack of information and time, and the age variable was statistically significant $(\mathrm{p}<0.05)$. In a study that was not parallel to our research, Kizıltan (1984) tested the compliance levels of university students and found that there was no age difference between adolescents. We can say that this difference is due to the fact that subjects aged 25 and over have increased their level of consciousness compared to other lower age groups, and they feel better in terms of individual psychology in our study.

It was determined that there was no statistically significant difference between the sub-dimensions of individual psychology, lack of knowledge, lack of facility, lack of time and interest, and class variable from the subdimensions of the leisure barriers scale of the participants participating in our study $(p>0.05)$. The difference between the lack of friends sub-dimension of the leisure time barriers scale and the class variable was found to be statistically significant $(\mathrm{p}<0.05)$. It can be said that female students who have just started university have not yet made friends and that feeling alone is effective in creating leisure barriers. The results obtained in the study conducted by Lakot (2015) are compatible with our study, it is seen that the study group participants have a high level of leisure time awareness and their leisure time barriers are high. It was determined that there was no statistically significant difference between the sub-dimensions of individual psychology, lack of knowledge, facility, lack of time and friends, and branch variable from the sub-dimensions of the leisure barriers scale of the participants participating in the study $(p>0.05)$. The difference between the lack of interest sub-dimension, which is one of the sub-dimensions of the leisure time barriers, and the branch variable was found to be statistically significant $(\mathrm{p}<0.05)$. It was found that female participants interested in individual sports had higher leisure barriers scores when the variables were examined. Despite all this data, the difference between variables was not significant. It has not been discussed in the literature due to the lack of sufficient studies about the branch variable. 
As a result; For female undergraduate students studying at Firat University Sports Sciences Faculty; It was seen that the difference between the leisure time barriers sub-dimensions and the department variable they studied was not statistically significant. It was seen that the difference between the sub-dimensions of the leisure barriers scale and the variables of age, class and branch was statistically significant. According to our study, the free time barriers scale scores of female undergraduate students studying in the sports science faculty departments of Firat University are 2.79 in the sub-dimension of individual psychology, 2.77 in the sub-dimension of lack of knowledge, 3.17 in the sub-dimension of the facility, 2.58 in the sub-dimension of lack of friends, 3.09 in the sub-dimension of time and 2.85 in the sub-dimension of lack of interest. When looking at the overall score average of the leisure barriers scale, it was observed that it was higher than the average with an average of 2.88 .

It is very important for individuals to spend their recreation time effectively, especially during work and school times. When the individual spends her leisure time effectively, she feels relaxed both psychologically and mentally. In line with all this relief, this mental state will relieve the person at work time and positively affect her communication with her social environment. In addition to all these, it is thought that it is of great importance that universities and state mechanisms make investments in terms of facilities and places in order for young people to spend their recreational time actively. Based on all this information it was necessary to check the levels of leisure barriers of female students in the study group. This study is thought to help sports scientists, psychologists and academicians working on this issue.

\section{References}

Alexandris, K., \& Carroll, B. (1997a). Motives for recreational sports participation in Greece. Insiation for the planning and provision of sports services. European Journal of Physical Education, 3(2), 129- 143.

Büküşoğlu, N., \& Bayturan, A. F. (2005). The role of leisure activities on the perception of psycho-social situations of young people. Ege Medical Journal, 44(3), 173-177.

Güler, H. (2017). Investigation of the effect of leisure obstacles on leisure motivations of students studying in physical education and sports colleges (Bartın University example). Master's Thesis, Bartın University, Institute of Educational Sciences.

Gürbüz, B., Öncü, E., \& Emir, E. (2012). Leisure contraints questionnaire: Testing the construct validity. Paper presented at the 12 th International Sports Sciences Congress, 339-343, 12-14 December, Denizli, Turkey.

Karahuseyinoglu, M. F., Altungul, O., Nacar, E., \& Tutar, O. F. (2020). Examination of the levels of digital game dependency of the students of the faculty of sports. Asian Journal of Education and Training, 6(1), 18-22.Available at: https://doi.org/10.20448/journal.522.2020.61.18.22.

Kızıltan, G. (1984). Factors affecting the personal and social cohesion levels of university students. Doctoral Thesis. Hacettepe University. Ankara.

Lakot, K. (2015). Free time perception and obstacles in physical education teacher candidates. Unprinted Master's Thesis, Karadeniz Technical University Institute of Educational Sciences, Trabzon.

Turkmen, M., Kul, M., Genç, E., \& Sarıkabak, M. (2013). Evaluation of recreation perceptions and attitudes of accommodation managers: Example of the Western Black Sea Region. Turkish Studies, 8(8), 2139-2152.

Turkoglu, Ç. (2009). The relationship between physical education teachers and high school students taking physical education classes with their attitudes towards the environment of their participation in environmental leisure activities is an example of Sincan district of Ankara province. Master's Thesis, Gazi University / Institute of Educational Sciences. Ankara. 